\title{
THE RELATION BETWEEN INVASIVE AND \\ NON-INVASIVE TEAR BREAK-UP \\ TIME IN YOUNG ADULTS
}

\author{
BY \\ *AMAECHI, O. U. AND OSUNWOKE, C. M. \\ DEPARTMENT OF OPTOMETRY \\ ABIA STATE UNIVERSITY \\ UTURU-ABIA STATE, NIGERIA \\ Email address: okamaechi@yahoo.com \\ *Corresponding author
}

\begin{abstract}
Tear stability normal to Nigerians with consideration of gender and age has not been reported. Tear stability in young adults was measured using invasive and non-invasive tear break-up time (TBUT and NIBUT). Forty ï five subjects aged 20 to 30 years were selected from among the students of University of Benin, Edo State. NIBUT was measured by noting the time taken for distortion or diffusion or diffusion of the Keratometric mires on the corneal surface while TBUT was assessed by noting the time taken for dry spots to appear on fluorescein treated eye. The mean NIBUT of the sample was $15.3 \pm 3.0$ seconds and 15.2 \pm 3.1 seconds for TBUT. The relation between TBUT and NIBUT was not statistically significant $(\mathrm{P}>0.05)$. The difference in mean TBUT and NITBUT was also not significant $(\mathrm{P}>0.05)$. There was no significant difference in mean TBUT and NIBUT between males and females $(\mathrm{P}>0.05)$. TBUT and NIBUT values were independent of subject's age. The TBUT values were comparable to NIBUT values and as such either of the two techniques can assuredly be used to assess the tear film stability. The status of the tear stability would help in selecting suitable candidates for contact lens wear.
\end{abstract}

KEYWORDS: Corneal surfaces, Tear film, Non-invasive tear break-up time (TBUT), Invasive tear break-up time (NIBUT), Stability.

\section{INTRODUCTION}

The ocular surface, tear film, lacrimal glands and eyelids act as a functional unit to preserve the quality of the refractive surface of the eye and to resist injury and protect the eye against changing bodily environmental conditions. The tear film is the most dynamic structure of the functional unit and prevents the desiccation of the underlying tissue while providing a smooth, optically refracting interface ${ }^{1}$. The most indicative test of the tear film and the ocular surface overall status is tear film stability. Evaluation of the tear stability can be done by either invasive (application of substance on the eye) or non-invasive (without applying any substance) methods.

Tear film break-up time is the interval between a complete blink and the first randomly distributed dry spots. The normal precorneal tear film form a continuous covering over the corneal surface. Tear break-up time is the time needed after blinking of the fluorescein treated eye for the appearance of dark spots in the fluorescence of the tear film ${ }^{2,3}$. Norn ${ }^{2}$ first introduced the technique of assessing the invasive tear break-up time (TBUT) by the observation of the fluorescein-stained tear film, using cobalt-blue filter on slit-lamp. The time interval between complete blink and the first appearance of a black spot or streak in the tear film is denoted as the TBUT. The non-invasive tear break-up time (NIBUT), was the time taken for the keratometric mires on the corneal surface to be distorted/diffused after a complete blink ${ }^{4}$.

Abelson, et $\mathrm{al}^{5}$ posited that a correlation exists between ocular discomfort and tear film break-up time. The manifestation of ocular discomfort may stimulate the eye to blink, replenishing the tear film and providing protection of the ocular surface.

Cho, et $\mathrm{al}^{6}$ showed that the instillation of fluorescein did not cause any significant change in the NIBUT of Hong Kong (HK) - Chinese. However, Mengher, et $\mathrm{al}^{7}$, using non-invasive method (where a grid image was projected onto the corneal surface and distortion or discontinuity of the image was taken as a sign of tear break-up), found that instillation of fluorescein significantly decrease the tear stability.

$\mathrm{Cho}^{8}$ carried out a study on the reliability of a portable non-invasive tear break-up time test on HK-Chinese. The NIBUT of the subjects was measured. Measurements were performed eight 
times over a period of eight weeks to test reliability of the NIBUT test over time. The difference in the NIBUT taken on different days was not significant using Friedman two-way analysis of variance. For the clinical estimate of the NIBUT, they recommended taking five measures of NIBUT and average the three closest measures and use as the mean value of the tear stability for the subject.

Cho and Douthwaited ${ }^{9}$ studied the relation between TBUT and NIBUT. They measured the TBUT and NIBUT on four groups of subjects from different countries (two groups of Caucasians, two groups of Chinese). No significant difference was found in either TBUT or NIBUT values among the four groups of subjects. They also found that gender had no effect on either TBUT or NIBUT.

Mohidin, et al $^{10}$ measured NIBUT in normal Malays by noting the time taken for distortions to appear in a reflected image of a grid pattern formed on the corneal surface. They reported that the gender had no effect on NIBUT. It was also shown that NIBUT decreases with age. Norn ${ }^{2}$ and Lemp and $\mathrm{Hamil}^{3}$ reported that TBUT was independent of the patient's age. Other studies showed an increase with age in the number of BUT values of less than 10 seconds $^{4,11,12}$.

Up till now there appear to be no studies of NIBUT and the comparison between NIBUT and TBUT in the Nigerian population. The aim of this study is to establish normal NIBUT and TBUT values.

\section{MATERIALS AND METHODS}

We used fluorescein strips and Burton lamp to assess the invasive tear break-up time (TBUT). The non-invasive tear break-up time (NIBUT) was assessed by using Bausch and Lomb Keratometer with CAT. N0. $71-21-35$ and serial No. 10115YY manufactured in USA. This was similar to that used by Patel and Farrell ${ }^{4}$.

Forty-five subjects ( 24 males and 21 females) aged 20 to 30 years with mean age of $23.3 \pm 2.6$ years from among the students of University of Benin were used for this study. All subjects were healthy and normal with no history of eye disease or surgery. They were not on any medication and had no history of contact lens wear. Informed consent to participate was obtained from all subjects.

All measurements were made in one room with relatively constant temperature and humidity. The NIBUT was first assessed and then TBUT for each subject.

Five measurements were made for each subject (right eye only) and the average of three closest NIBUT values was taken as the mean value. This procedure increases the reliability of the technique ${ }^{8}$; the subject was seated carefully with chin on the chin rest and forehead on the headrest. The keratometer was then well adjusted and focused on the right eye with the mires in focus, the subject was asked to blink once and to refrain from blinking. A stopwatch was started after the last complete blink. At the first sign of any distortion of the mires, the stopwatch was stopped and the time noted. If the subject blinks between measurements, the test is halted, and then repeated after several blinks. The time interval between the last blink and the first sign of mire distortion was recorded in seconds as the NIBUT.

For the measurement of TBUT, the subject was seated comfortably and asked to look downwards. The upper lid of the right eye was slightly lifted and the fluorescein strip was then used to stain the eye. Subject was asked to keep the eyes open while looking straight ahead. The stopwatch was started after the last blink and the appearance of dry sports on the corneal surface was observed with the blue light of the Burton lamp. At the first appearance of the dry spots, the stopwatch was stopped. The time interval between the last blink and the first appearance of the dry spots was recorded in seconds as the TBUT.

Data obtained were analyzed using tables, student's T-test, Pearson's correlation analysis and analysis of variance.

\section{RESULTS}

The mean NIBUT was $15.3 \pm 3.0$ (SD) while that of TBUT was $15.2 \pm 3.1$ (SD) seconds for the sample population $(n=45)$. The difference in mean between NIBUT and TBUT was not statistically significant (Unpaired t-test: $\mathrm{t}=0.15, \mathrm{df}=88$, $\mathrm{P}>0.05)$. The degree of association between NIBUT and TBUT was not significant by Pearson's correlation coefficient $(\mathrm{r}=0.04, \mathrm{P}>0.05)$ and the regression line was not also significant by analysis of variance $(=0.8, \mathrm{df}=1, \mathrm{P}>0.05)$. Similarly, the degree of association between NIBUT and age was not significant. Also, there was no relation between TBUT and age.

The difference in mean NIBUT between males and females was not statistically significant (Unpaired t-test: $\mathrm{t}=0.30, \mathrm{df}=43, \mathrm{P}>0.05$ ). Similarly, there was no significant difference in mean TBUT between males and females $(\mathrm{t}=0.08$, $\mathrm{df}=43, \mathrm{P}>0.05)$. The means standard deviation and confidence interval of NIBUT and TBUT for males 
were presented in table 1 . Table 2 showed the mean standard deviation and confidence interval of NIBUT and TBUT for females. The mean, standard deviation and confidence interval of the sample were presented in table 3 .

\section{DISCUSSION}

The result obtained in this study showed that mean NIBUT was $15.3 \pm 3.0$ seconds. This result is similar to that reported by $\mathrm{Cho}^{8}$ who reported a mean NIBUT value of 16.0 \pm 9.4 seconds for Hong Kong-Chinese and Monhidin, et $\mathrm{al}^{10}$ found a mean of 15.9 \pm 9.4 seconds in normal Malays population. However, the result differs from that reported by Mengher et $\mathrm{al}^{7}$ who found a mean value of $47.9 \pm 5.3$ seconds and a median value of 62 seconds for Caucasian subjects. The mean TBUT was $15.2 \pm 3.1$ seconds. The difference in mean NIBUT and TBUT was not significant. This was consistent with the findings of Cho and Douthwaite ${ }^{9}$ who reported that no significant difference was found in either TBUT or NIBUT values among four groups of subjects they worked with.

With normal subjects, Lemp and Hamil ${ }^{3}$ found that the majority of TBUT fell in the 15 to 34 seconds range, and that in no instance was it less than 10 seconds. The mean value of 15.2 seconds obtained for TBUT in this study was the lower limit to the range. A break-up of less than 10 seconds is usually considered a negative factor in patient's selection for contact lens fitting, particularly in regard to the fitting of soft lenses ${ }^{3}$.

This study has demonstrated in a way that the instillation of fluorescein did not disrupt the tear film stability going by the direct comparison of the mean values of the NIBUT and TBUT. This is in agreement with the study of Cho, et $\mathrm{al}^{6,}$ who reported that instillation of fluorescein, did not cause any significant change in the NIBUT of asymptomatic Hong Kong-Chinese subjects.

The result also showed that neither NIBUT nor TBUT was affected by age. This was in agreement with earlier studies ${ }^{2,3,13}$ that reported that tear stability was independent of age. The nonsignificance of the association between NIBUT or TBUT and age in this study may have been due to the narrow age range of 20 to 30 years. Gender was also shown to neither affect the NIBUT nor TBUT. This is in line with previously reported studies ${ }^{4,9,10,14,15}$.

In conclusion, we found the mean NIBUT and TBUT values of young Nigeria adults to be $15.3 \pm 3.0$ and $15.3 \pm 3.1$ seconds respectively. Both NIBUT and TBUT values were not dependent on age. There was no significant difference in NIBUT and TBUT between males and females. This study has shown that the tear film stability can be assuredly evaluated by either of the two techniques by eye care practitioners with a view to selecting candidates for contact lens wear especially soft lenses.

TABLE 1: MEAN, STANDARD DEVIATION AND 95\% CONFIDENCE INTERVAL OF NIBUT AND TBUT FOR MALES

\begin{tabular}{|l|l|l|}
\hline $\begin{array}{l}\text { Techniques for assessing } \\
\text { Tear stability }\end{array}$ & $\begin{array}{c}\text { Mean } \pm \text { SD } \\
(\text { Seconds })\end{array}$ & $\begin{array}{l}\text { 95\% Confidence } \\
\text { interval Mean } \pm \text { SEM }\end{array}$ \\
\hline NIBUT & $15.4 \pm 2.7$ & 14.2 to 16.6 \\
$\mathrm{~N}=24$ & $15.2 \pm 3.4$ & 13.8 to 16.6 \\
\hline TUBT & & \\
N=24 & & \\
\hline
\end{tabular}

TABLE 2: MEAN, STANDARD DEVIATION AND 95\% CONFIDENCE INTERVAL OF NIBUT AND TBUT FOR FEMALES

\begin{tabular}{|l|l|l|}
\hline $\begin{array}{l}\text { Techniques of } \\
\text { Assessing Tear } \\
\text { stability }\end{array}$ & $\begin{array}{l}\text { Mean } \pm \text { SD } \\
\text { (Seconds) }\end{array}$ & $\begin{array}{l}\text { 95\% Confidence } \\
\text { Interval Means } \pm \text { SEM }\end{array}$ \\
\hline $\begin{array}{l}\text { NIBUT } \\
\text { N }=21\end{array}$ & $15.1 \pm 3.4$ & 13.5 to 16.7 \\
\hline $\begin{array}{l}\text { TUBT } \\
\text { N }=21\end{array}$ & $15.1 \pm 2.7$ & 13.8 to 16.4 \\
\hline
\end{tabular}


TABLE 3: MEAN, STANDARD DEVIATION AND 95\% CONFIDENCE INTERVAL OF NIBUT AND TBUT FOR SAMPLE POPULATION

\begin{tabular}{|l|l|l|}
\hline $\begin{array}{l}\text { Techniques of } \\
\text { Assessing Tear } \\
\text { stability }\end{array}$ & $\begin{array}{l}\text { Mean } \pm \text { SD } \\
\text { (Seconds) }\end{array}$ & $\begin{array}{l}\text { 95\% Confidence } \\
\text { Interval Means } \pm \text { SEM }\end{array}$ \\
\hline $\begin{array}{l}\text { NIBUT } \\
\text { N }=45\end{array}$ & $15.3 \pm 3.0$ & 14.4 to 16.2 \\
\hline $\begin{array}{l}\text { TUBT } \\
\text { N }=45\end{array}$ & $15.2 \pm 3.1$ & 14.3 to 16.1 \\
\hline
\end{tabular}

\section{R E F E R E N C E S}

1. Moses, R. A. and Hart, W. M. Jr. (1987): Adler's Physiology of the eye: Clinical Application. $8^{\text {th }}$ Edn. C.V. Mosby Co, St. Louis, MO, 689pp.

2. Norn, M. S. (1969): Desiccation of the precorneal film. I. Corneal wetting time. Acta Ophthalmol; 47: 865-80.

3. Lemp, M. A. and Hamil, J. R. (1973): Factors affecting tear film break-up in normal eyes time. Acta Ophthalmol, 89:103-5.

4. Patel, S. and Farrell, J. C. (1989): Age-related changes in precorneal tear film stability. Optom. Vis. Sci, 66:175-8.

5. Abelson, E., Ousler, P. and Humphrey, S. (1993): Non-invasive tear break-up time. Acta Ophthamol, 56:22-9.

6. Cho, P., Hok, Y., Huang, Y. C., Chui, H. Y. and Kwan, M. C. (1994): Comparison of noninvasive tear break-up time measurements from black and white background instruments. Optom. Vis Sci, 81(6): 436-41.

1. Mengher, L. S., Bron, A. J., Tonge, S. R. and Gilbert, D. J. (1985): A non-invasive instrument for clinical assessment of pecorneal tear stability. Curr. Eye Res. 4:1-7.

2. Cho, P. (1993): Reliability of a portable noninvasive tear break- up time test on Hong
Kong-Chinese. Optom. Vis. Sci. 70:1049-54.

3. Cho, P. and Douthwaite, W. (1995): The relation between invasive and non-invasive tear break-up time. Optom. Vis. Sci, 72: 17-22.

4. Mohidin, N., Bay, T. C., and Yap, M. (2002): Non-invasive tear break-up time in normal Malays. Clin. Exp. Optom. 85(1):37-41.

11. Zhang, H. C. (1990): An investigation of vital staining of the ocular surface and BUT of the tear film in Chinese. Chin. J. Ophthalmol, 26:43-6.

12. Paschides, C. A., Petroutsos, G., and Psilas, K. (1991): Correlation of conjunctival impression cytology results with lacrimal function and age. Acta Ophthalmol, 69: 422-5.

13. Vanley, G. T., Leopold I. H and Gregg, T. H. (1977): Interpretation of tear film break-up. Acta Ophthalmol, 95:445-8.

14. Cho, P. and Brown, B. (1995): The effect of benoxinate on the tear stability of Hong KongChinese. Ophthalmol. Physiol. Opt, 4: 299304.

15. Tonge, S. R., Hunsaker, J and Holly, F. J. (1991): Non-invasive assessment of tear film break-up time in a group of normal subjectsimplication for contact lens wear. J. Br. Cont. lens Assoc, 14:201-5. 